\title{
New Orleans Educational System in Public Schools Pre/Post Hurricane Katrina as Perceived by Special Education Teachers
}

\author{
Sultan Alzahrani ${ }^{1, *}$ \\ ${ }^{1}$ Special Education Department, University of Jeddah, Jeddah city, Saudi Arabia \\ *Correspondence: Special Education Department, University of Jeddah, Jeddah city, Saudi Arabia. E-mail: \\ ssaalhariri@uj.edu.sa
}

Received: March 20, 2018

Accepted: April 5, 2018 Online Published: April 11, 2018

doi:10.5430/wje.v8n2p88

URL: https://doi.org/10.5430/wje.v8n2p88

\begin{abstract}
This modified narrative study is an exploration of the perceptions of two special educators who experienced the dramatic changes in the New Orleans public school system as a result of Hurricane Katrina. The participants in this study will consist of two special education professionals (See Table 1). From their perspectives, the reader shall gain a deeper understanding of how the educational system has evolved from its pre-Katrina structure.
\end{abstract}

Keywords: Katrina, special education, new orleans, culture, collaboration, socioeconomic, open system, contingency theory, administration \& leadership

\section{Introduction}

Prior to 2005, the New Orleans educational system faced major academic, economic, and structural issues (Beabout, 2007; Mirón, 2008). At this time, the parish was substantial in size with over 100 public K-12 schools (Hill \& Hannaway, 2006). "The public schools of New Orleans have long been believed to be among the worst of any big city school systems in the United States” (Beabout, 2007, p. 43). In the 2004-2005 school year, not even half of all Orleans Parish fourth graders proved proficient in reading and only about one in four were proficient in math; in addition, three quarters of parish schools received an "academic warning" or were considered "academically unacceptable (Hill \& Hannaway, 2006). Due to low performance and the migration of affluent White students into private and catholic schools, the city of New Orleans had one of the highest student attendance rates in private education (Newmark \& De Rugy, 2006; Beabout, 2007).

Table 1. Demographics of the Special Education Teachers Who Participated in the Study

\begin{tabular}{lll}
\hline & Teacher 1 & Teacher 2 \\
\hline Years of Experience & 20 & 18 \\
Level of Education & Master's Degree+ Ph.D. Students & Bachelor's Degree \\
Ages & 43 & 39 \\
Gender of Teachers & Female & Female \\
Specialization & Special Education & Special Education \\
Current Job Title & Administrator & Special Ed. Teacher \\
\hline
\end{tabular}

On August 29, 2005 the city of New Orleans was devastated by the remnants of Hurricane Katrina as a result of breached levees. Many of the residents were displaced, downtrodden, and in dire need of resources for daily survival due to immense flooding. Feeling abandoned by their local, state, and federal government agencies because of lack of support, many citizens were unable to make a swift return to the normalcy they once knew (Wynne, 2007). The impact of Hurricane Katrina compounded already existing inadequacies in Orleans parish schools, which lead to the literal deconstruction of the education system. From this desolation, the district briefly lost its typical students and students with disabilities population because of lack of resources and struggled to reopen schools (Beabout, 2008). In Orleans Parish, only 20 public school buildings were found suitable for occupancy after Hurricane Katrina in comparison to the 120 useable school buildings prior to the storm (Hill \& Hannaway, 2006). Therefore, school board 
members made the conscious decision to terminate teaching positions (Beabout, 2007). State government officials in Louisiana decided that the best way to rebuild schools was through the recovery school system, and through the commissioning of charter schools (Beabout, 2008). As a result, New Orleans Public Schools (NOPS) only retained five public schools (Beabout, 2008).

\section{Purpose Statement}

This narrative study will address the academic, economic, social, and structural changes made to the New Orleans Public School System which may affect the general and special education programs as experienced through two special educators in this region. Through their perceptions, I will approach the issues faced by the New Orleans Public Schools prior to Katrina, and how these issues were affected by the disaster. The impact of Katrina on the school system in both general and special education programs created a phenomenon of change that must be explored.

\section{Significance}

The exploration of the lived experiences of special educators who survived physically and professionally the events of Hurricane Katrina is important because it gives a voice to those striving to reconstruct the concept of education. In addition, their perspectives will provide a deeper understanding of how a natural phenomenon altered the structure of a large urban education system. The findings from this study will help the reader understand these educators' perspectives on how traumatic events such as Hurricane Katrina can impact special education programs and K-12 school system in general.

\section{Research Questions}

This analysis leads to the following research questions for this study. These questions may evolve based on the data collected.

1) What were the perceptions of special educators in New Orleans public school system pre-Katrina?

2) What were the perceptions of special educators in New Orleans public school system post-Katrina?

\section{Narrative}

Both of the participants started their narratives off by stating that they were happy working in New Orleans Public School System before Hurricane Katrina. When discussing their pre-Katrina experience, Mona stated, "We had to get back so my husband could get back to work but I was ready to come home and teach.” In a similar vein, Nany recalled, "Before the storm, I worked in New Orleans Public School System for five years as special education teacher and my experiences were okay and the students with disabilities were the first priority," "People used to talk about how flawed the system was before, but I find the system to be more flawed now."

Both educators described the experiences they encountered due to evacuation and the rebuilding of their lives. Mona was able to leave New Orleans before the storm whereas Nany was unprepared for evacuation. Following the storm, Mona was able to immediately return to New Orleans due to her husband's job, while Nany relocated briefly to Texas then to Franklin, Louisiana to live with family. Although both participants returned under different circumstances, they both had a strong desire to return to New Orleans and the classroom. There was a strong connection to the city as well as to the teaching profession that pushed both ladies to defy the odds placed before them. These themes represent their stories.

Shortly after their return, both educators began working for charter schools. As Mona stated, Charter schools have changed the face of the educational landscape of New Orleans. Whether it was the culture, the collaboration, or the financial fidelity, she believed that the influx of charter schools created a deep atmosphere of change.

One of the most obvious changes in the months following the storm was the change to school names. Before Hurricane Katrina, the people in New Orleans based their identity on the school in which they attended. Mona mentioned "[In] the culturally rich city, education wasn't the end all, be all, or that it was great or fantastic, but New Orleanians align themselves and identify themselves by their school." Now, suddenly, the schools that so many New Orleanians identify themselves with as youths were being taken over by large charter school management operators such as KIPP, First Line, and ReNew.

This change in operation resulted in many other school structural changes. Schools became more site based and 
performance driven, and resources differentiated as well. Administrators had to reevaluate the way they approached their duties, the students, the parents, and even their faculty and staff. Most of the special education programs trimmed the number of students get their services. The number of special education teachers was limited at that time. Curriculum and funding became a site-based battle, while traditional charter school landscapes were challenged. In effect, the influx of charter schools after Hurricane Katrina changed the educational landscape of New Orleans forever.

\section{Culture}

According to participant Mona, the culture of her school has become diverse as a result of Hurricane Katrina. Prior to the storm, the majority of her student body consisted of White students due to the school being located in an affluent uptown New Orleans neighborhood. Since the hurricane, the school has become all-encompassing by ushering in an assorted mix of students. This change was an initial shock to campus culture, but as Mona states, “...it's taken a while for the older people and parents and people who've been in the old culture to come around.” Blending and coming together as one has made the charter school a staple in the community therefore allowing it to match the culturally rich atmosphere of the city.

In addition, Mona also spoke about how administrators were responsible for the campus culture, and how she believes this is a large part of why her school is successful. To gain student buy-in, administrators believed in school spirit. This was displayed in the form of school colors and student artwork placed throughout the hallways. A strong parental support also aided the school with student success; this can be attributed to ambitious teachers and administration. As far as the faculty culture goes, Mona stated, "I'm all about teamwork" and "teamwork makes the dream work." She believes it is the administrator's responsibility to facilitate an environment that provides a positive and conducive atmosphere for the learning environment.

Participant Nany's perspective of the culture differed from Mona. Nany works as special education teacher at a lower socioeconomic charter school and perceives that the school culture has declined since Hurricane Katrina. Prior to Hurricane Katrina, Mona felt that her coworkers were her family. Nany states, "There was no revolving door where every year there was a new set of teachers coming in. It was the same staff year after year. We may have had one or two people in or out for various reasons. Therefore, we were able to establish bonds amongst one another, that still to this day we are friends.” Nany feels that post Hurricane Katrina the school system, specifically charter schools, "operate in that spirit of fear and intimidation." According to Nany, "...teachers are now afraid to share and afraid to ask others for support. They [teachers] are not aware if it is genuine or sabotage, because everyone now has to make themselves look good. Everybody data has to be awesome so that at the end of the year you'll get a letter saying that we want you to return... Instead of creating that culture you are creating dissection among your teachers. Everybody works in isolation now. The very thing we were taught not to do."

Nany's frustration from a lack of a supportive culture in the New Orleans public school system has caused her to seek a new career. Prior to the storm Nany stated, "When I entered the teaching profession, my intent was to start at one school and retire from that one school." Now with the culture Nany reveals, "I am student at Delgado right now. I am up to my eyeballs in student loan debt and I will gladly borrow more money to get out of the teaching profession."

\section{Collaboration}

Mona attested that since Hurricane Katrina, "People who would normally be able to live and be a part of a neighborhood can no longer be that way after Katrina." This meant that the children in local neighborhoods might not attend the school just a few blocks away. Mona observed that this created a loss in the sense of community support and parental support. She believes that this change in culture and climate have also affected the parental collaboration. Mona stated, "Our parent community, I love them, but they are very demanding. The school is a responsibility to work and advocate for all children, not just one child. As a parent, you come to advocate for just one child."

Mona was quick to point out that the parents who could not provide this same level of involvement also affected this collaboration. According to her, "The parents are just involved to the extent that they could be. Parents of low performing schools, every parent sends us the best that they can.” Mona believes it is her role as a special education teacher in the past and as an administrator now to navigate these two extremes and keep a collaborative environment between the school and parents. However, after Katrina there were many new faces that resulted in a loss that sense of family and collaboration. 
Contradictory, Nany believes that after Katrina, there was a lack of both special and general education teachers support, and that some of the leaders became less collaborative with their staff. Nany mentioned that "Post Katrina non-traditional leaders come with non-traditional ways and they want things implemented without collaboration or support from the teachers.” This lack of educational background, she believes, led to an operation of fear which greatly influenced teacher collaboration.

On the other end of the spectrum, Mona believes that site-based management that is now present in schools allows her a certain level of autonomy which in turn allows her to give more power to her teachers. In Mona's school, she allows teachers to make most of the decisions that pertain to the classroom, and the faculty has frequent team collaboration meetings to ensure that this process is effective. She believes that the teachers are the experts in the classroom and that by giving them power over their own classrooms, it creates a better environment for collaboration and teacher buy-in which positively affect the school environment including special education programs.

\section{Socioeconomic}

Both participants viewed the financial aspects of the school system before Hurricane Katrina poorly. They spoke about the low pay teachers received and the conditions of the buildings they worked in. However, after Hurricane Katrina their experiences differed.

Mona stated, "Katrina was a blessing to New Orleans, it brought in funds to improve the buildings.” Restructuring of buildings and students played a large part in how the money was allocated. As an administrator, Mona believes that she is very well compensated and that the system is better off.

Nany's account is very different, "I'm a contract employee, meaning I get to negotiate my salary." Even though she thought the pay was a little better, it was not fair. In her eyes, her experiences and expertise in the field of special education were not accounted for. She stated, "Before Hurricane Katrina there was a pay scale." She knew when she would receive her step increase (raise) and how much it would be.

In regards to resources, Nany felt that the availability of resources was dependent on which charter school you worked for and what resources your leader deemed important. She recounted experiences, with a principal who was very supportive and worked hard to make sure all resources were available to assist the academic learning process for both typical students and students with special needs. She also recounted experiences when she asked the administrator for additional resources and she was told to use the internet. Because Mona was an administrator her outlook differed from Nany. Mona's outlook on the financial aspect was global and positive. However, Nany's was more personal. Her thoughts were connected to how she and other teachers were personally affected. Although these two educators shared many similar experiences, their overall experiences have many differences.

\section{Data Interpretation}

After conducting my interviews, I found several common themes presented by the participants. These themes consisted of the participants' journey back home, the charter school movement, school culture, special education teacher / administrator collaboration, and financial implications. Although these themes were similar between both participants, their narratives show two very different experiences. What had caused these differences in their experiences? I analyzed the data, and found two main variations in their stories: the socioeconomic status of the school, and the approaches to administration of the school.

\section{Administration \& Leadership}

During my interviews, Mona and Nany consistently placed emphasis on the role and importance of leadership in their experiences. In some schools, such as Mona's, administrators pushed a collaborative environment post Katrina that supported teachers and the rebuilding of their educational community. While Mona stated that there were some limitations due to the bureaucracy of education, she believed that the way in which an administrator handled that bureaucracy directly influenced collaboration in her school. "Yeah, there are some decisions that are going to have to be me, but I like to look at us like a circle where we are links in a chain and we are arm in arm." She also believed that choosing the right team was one of the important challenges facing the leaders of schools after the storm. "I hear horror stories all the time about 'oh we have an island of excellence' who likes to work on their own. But it's our job as leaders to find out what makes that person tick to get them to be a part of the culture and climate."

Nany, on the other hand, believed that lacking collaborative leadership ruined her perception of being a special education teacher. "[Pre-Katrina], I could get support from [other teachers] in the area of behavior, curriculum, and 
discipline because no one felt threaten by the other person. Post Katrina, it is totally opposite. There is no time to build those bonds." Nany believes that the demand for production, as opposed to teaching, is pitting teachers against each other in a "spirit of fear." "Nontraditional Leaders come with nontraditional ways and they want things implemented without collaboration or support from the teachers." "I don't trust the teachers I work with to help support my toolbox."

This type of plug and chug machine system creates serious issues for all involved (Etzioni, 1964; Freire, 1993; Mitzenberg, 1979; Morgan, 2007). First, it removes the natural abilities of teachers by making them vessels aimed at delivering watered-down content to student receptacles (Freire, 1993). When these teachers fail to perform as directed by administrators such as on standardized tests, they are removed and replaced with a new machine piece especially in the special education program, (Mintzberg, 1979; Morgan, 2007). This type of machine treatment breaks down the human spirit of the teachers and students, creating the feeling of competition as opposed to community that Nany described (Friere, 1993; Morgan, 2007). The administrator's role as a machine operator is to serve as the power structure needed to cultivate Nany's desire to educate students.

\section{Analysis}

From my narrative interviews, I concluded that socioeconomic status was a crucial element to educator's perception of the New Orleans public school system in general and of course special education programs in specific post Hurricane Katrina. Prior to Katrina, money was allocated from the district based on school needs and Title I funding. As a result of this, schools that were located in low-income neighborhoods were not diverse and did not receive adequate funding to assist with school improvement (Cowen Institute for Public Education Initiatives, 2013). Because of destroyed neighborhoods, the district did not have the capital to rebuild schools; consequently, there was an influx of charter schools formed.

Socioeconomic status (SES) and its effects on educational realization in the K-12 system have been investigated for several years (Walpole, 2003). Mitchell and Leachman (2015) disclosed that currently less funding is given per student in 34 states than prior to the recession. As a result of less funding, typical students and students with disabilities from lower SES circumstances not only suffer from a lack of resources at home but also suffer from minimum resources at schools. Many of the schools funded by property and local taxes in poor areas are unable to keep pace. Therefore, in order to sustain themselves after Hurricane Katrina, it was crucial that the surrounding environment be taken into consideration.

\section{A. Open System}

According to Lunenburg (2010), an open system is a system that has external interactions that consist of five basic elements: inputs, a transformation process, outputs, feedback, and the environment. The New Orleans Public School System faced various changes in aspects of operation such as the restructuring of school zones, financial funding, seizure by the Recovery School System, and the implementation of charter schools. New Orleans Public School System was directly impacted by its environment and had to restructure themselves to deal with the forces surrounding them. As a result of the environmental issues, the internal structure of the school system and the special education programs in the schools changed. Schools had to adapt to the lack of funds, shortage of general teachers, special education teachers, and students, as well as inadequate facilities. Morgan (2006) states that "The internal regulatory mechanism of a system must be diverse as the environment with which it is trying to deal. Only by incorporating required variety into internal controls can a system deal with the variety and challenge posed by its environment."

New Orleans has a history of being culturally rich and diverse city, but the school system was not always representative of this. Post Katrina, the school system has become more encompassing, where a diverse school according to Dreilinger (2015) is now one that has White students. Since the storm, there has been a 7 percent increase in White students in New Orleans public schools (Dreilinger, 2015). This increase could be contributed to the new way of managing schools as ascribed in contingency theory.

\section{B. Contingency Theory}

Adaptation to the environment is vital to an organization's survival. Contingency theory is based on the premise that organizations are open systems that need careful management to satisfy and balance the internal needs and environmental circumstances (Morgan, 2006). Therefore, it is important that there is a working relationship between all vested stakeholders. This relationship must consist of trust and mutual respect for all parties. Morgan (2006) states that the main underlying concepts in Contingency Theory are: 
1. The best way of handling situations depends on the kind of task or environmental issues or concerns that the organization is dealing with;

2. Managements concern with attaining structure and good fits; and

3. Different approaches to management may be required to perform different tasks within the same organizations.

Based on this study, educators seemed more receptive to leaders who were task oriented, and student centered. Educators were also more accepting of leaders who were effective communicators, nurturing, supportive, and encouraging. These experiences varied between participants but were the underlying factors for success and intrinsic happiness.

\section{Conclusion}

From this study I learned that special educators' perspective varied differently post Hurricane Katrina. Prior to the storm, the nature of the public education system was not perfect but an intangible culture existed amongst faculty, staff, students, and parents. Following the storm, the perspective of both two special educators changed as a result of charter schools. These changes could be attributed to finances, administration, and school location. To better gauge these differences amongst educators, a broader sample size must be studied to better understand the perception of New Orleans educator’s pre/post Hurricane Katrina.

\section{References}

Beabout, B. R., Carr-Chellman, A. A., Alkandari, K. A., Almeida, L. C., Gursoy, H. T., Ma, Z., \& Pastore, R. (2008). The perceptions of New Orleans educators on the process of rebuilding the New Orleans school system after Katrina. J Educ Stud Placed at Risk, 13(2-3), 212-237. https://doi.org/10.1080/10824660802350185

Beabout, B.R. (2007). Stakeholder organizations: Hurricane Katrina and the New Orleans Public Schools. Multicultural Education, 15(2), 43-49.

Cowen Institute for Public Education Initiatives. (2013). The state of Public education in New Orleans: 2013 Report Retrieved from http://www.coweninstitute.com/wp-content/uploads/2013/07/2013_SPENO.pdf

Dreilinger, D. (2015, September 3). Has gentrification begun in New Orleans public schools?. Retrieved from http://www.nola.com/futureofneworleans/2015/09/bricolage_morris_jeff_interest.html

Etzioni, A. (1964). Administrative and professional authority. In Modern Organizations (p. 75-84). Englewood Cliffs, NJ: Prentice Hall.

Freire, P. (1993). Pedagogy of the oppressed (Rev. ed.). New York: Continuum, 1970.

Hill, P., \& Hannaway, J. (2006). The future of public education in New Orleans. In M. A. Turner \& S. R. Zedlewski (Eds.), After Katrina: Rebuilding opportunity and equity into the NEW New Orleans. Washington, DC: The Urban Institute.

Lunenburg, F.C. (2010). Schools as open systems. Schooling, 1(1), 1-5.

Mintzberg, H. (1979). The professional bureaucracy. In The Structuring of Organizations (p. 348-379). Englewood Cliffs, NJ: Prentice-Hall.

Mirón, L. (2008). The urban school crisis in New Orleans: Pre and post Katrina perspectives. Journal of Education for Students Placed at Risk, 13(2), 238-258. https://doi.org/10.1080/10824660802350193

Mitchell, M. \& Leachman, M. (2015, May 13). Years of cuts threaten to put college out of reach for more students. Center on Budget and Policy Priorities. Retrieved from http://www.cbpp.org/research/state-budget-and-tax/years-of-cuts-threaten-to-put-college-out-of-reach-for-morestudents

Morgan, G. (2007). Images of organization. Thousand Oaks, CA: Sage publications.

Newmark, K. G., \& De Rugy, V. (2006). Hope after Katrina. Education Next, 6(4).

Northouse, P. G. (2013). Leadership: Theory and practice. Thousand Oaks, CA: SAGE Publications.

process of rebuilding the New Orleans school system after Katrina. Journal of Education for Students Placed at Risk, 13, 212-237. 
Walpole, M. (2003). Socioeconomic status and college: How SES affects college experiences and outcomes. The Review of Higher Education, 27, 45-73. https://doi.org/10.1353/rhe.2003.0044

Wynne, J.T. (2007). The winds of Katrina still call our names: How do teachers and schools confront social justice issues? Multicultural Education, 15(2), 50-51. 